\title{
Muerte súbita en un joven por rotura de aneurisma sobre el seno de Valsalva derecho
}

\section{Sudden death in a young caused by rupture of an aneurysm above the right sinus of Valsalva}

\section{Resumen}

Los aneurismas de la porción proximal de la aorta pueden afectar a la raíz de la aorta, a los senos de Valsalva o a la aorta ascendente. En niños y jóvenes generalmente se asocian a enfermedades hereditarias del tejido conectivo, como el síndrome de Marfan, aunque también hay formas familiares no-sindrómicas en que la disección de aorta se presenta como patología aislada. Presentamos un caso de disección de aorta por rotura de un aneurisma localizado en la unión sinotubular derecha y comentamos su diagnóstico diferencial. Describimos los cuadros sindrómicos asociados a las disecciones de aorta proximal y comentamos la metodología en la autopsia forense para la detección de las formas hereditarias.

Palabras clave: Aneurisma de aorta. Disección. Seno de Valsalva.

\section{Abstract}

Proximal aortic aneurysms can involve aortic root, sinus of Valsalva or ascending aorta. In children and young individuals generally occur in the setting of an inherited connective tissue disorder as Marfan syndrome, although there are also familial non-syndromic forms of isolated aortic dissection. We describe an aortic dissection of an aneurysm of the right sinotubular ridge and discuss differential diagnoses. We review the syndromic disorders related to proximal aortic dissections and discuss the autopsy procedure for detection of inherited forms.

Key words: Aortic aneurysm. Dissection. Sinus of Valsalva.

\section{Introducción}

La disección es una complicación frecuente de los aneurismas de aorta torácica y su rotura a saco pericárdico da lugar a muerte súbita por taponamiento cardiaco. Los aneurismas de aorta torácica pueden afectar a la raíz de la aorta, aorta ascendente, arco aórtico, aorta descendente o una combinación de $a_{m b o s}^{1,2}$. En adultos se relaciona fundamentalmente con la hipertensión arterial, que produce debilidad de su pared, mientras que en niños y jóvenes es infrecuente y está relacionada con enfermedades hereditarias como el síndrome de Marfan, síndrome de Loeys-Dietz y el síndrome de Ehler-Danlos ${ }^{2-4}$. Los aneurismas proximales suelen producir una ectasia difusa de la aorta ascendente o una insuficiencia valvular (ectasia anuloaórtica) mientras que los aneurismas con afectación de la raíz de la aorta son típicos del síndrome de Marfan

Presentamos un caso de disección de aorta sobre un aneurisma localizado en la unión sinotubular derecha y comentamos su diagnóstico diferencial y la metodología en la autopsia forense para la detección de las formas hereditarias de la disección de aorta.

\section{Presentación del caso}

Se trata de un varón de 19 años que falleció súbitamente en su domicilio. Su padre por la mañana lo encontró inconsciente y respirando con dificultad.
MP. Suárez Mier ${ }^{1}$

E. Morandeira ${ }^{2}$

${ }^{1}$ Doctora en Medicina. Especialista en Anatomía Patológica.

Serv. de Histopatología. Instituto Nacional de Toxicología y Ciencias Forenses.

Las Rozas de Madrid.

${ }^{2}$ Médico Forense.

Subdirección de

A Coruña. Instituto de

Medicina Legal de

Galicia (IMELGA).

Correspondencia:

MP Suárez Mier

Servicio de Histopatología

Instituto Nacional de

Toxicología y Ciencias

Forenses

José Echegaray $n^{0} 4$

28232 Las Rozas (Madrid)

E-mail:

mariapaz.suarez@justicia.es

Fecha de recepción:

3.SEP.2012

Fecha de aceptación:

11.SEP.2012 
La noche anterior había salido. Los servicios de emergencia realizaron maniobras de reanimación durante 25 minutos sin resultado. Sin antecedentes pa-

Figura 1.

Detalle de la base cardiaca donde se observa dilatación aneurismática de la porción proximal de la aorta $y$ solución continuidad en el centro (flecha).

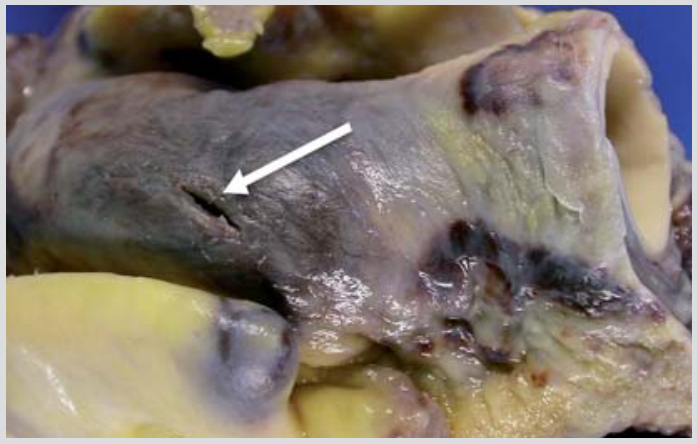

Figura 2 Imagen de la válvula aórtica en la que se reconocen tres velos (tricúspide) y se observa dilatación de la unión sinotubular y del seno de Valsalva derecho.

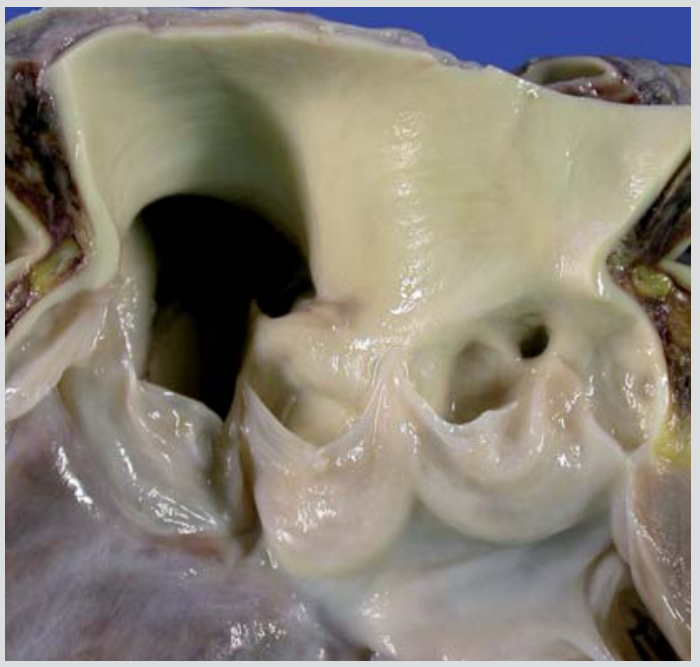

Figura 3.

Desgarro intimal en la raíz de la aorta que afecta al seno

de Valsalva y a la unión sinotubular. El ostium de la coronaria derecha está preservado (flecha).

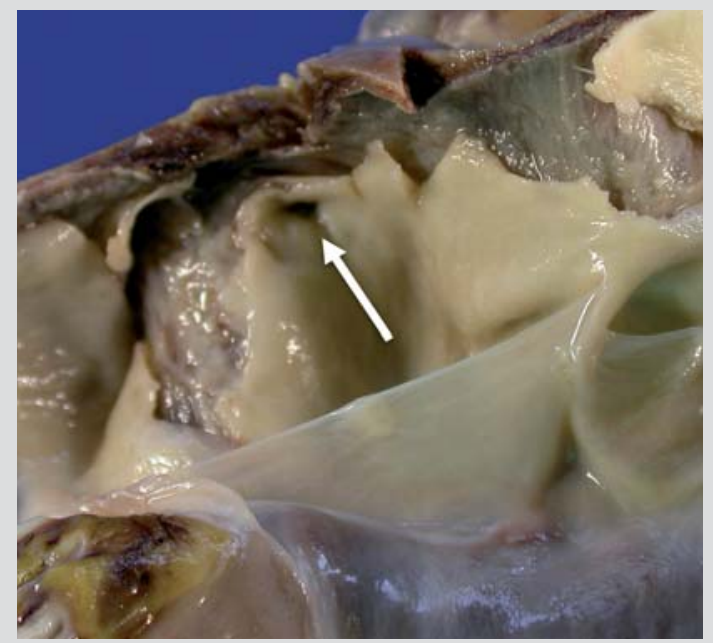

tológicos salvo, según declaración de su padre, dolor torácico los últimos 2-3 días. Tampoco había antecedentes de muerte súbita en la familia.

En el examen externo del cadáver no se encontraron lesiones significativas. Se trataba de un varón de $172 \mathrm{~cm}$ de estatura y complexión atlética. En el examen interno se observó un pericardio a tensión con más de $500 \mathrm{ml}$ de sangre y edema pulmonar. Los hallazgos extracardiacos fueron irrelevantes. El corazón, una vez fijado en formol, pesaba 407 g y existía una dilatación aneurismática con hemorragia de unos $4,5 \mathrm{~cm}$ de diámetro en la aorta ascendente proximal, con una solución de continuidad de $8 \mathrm{~mm}$ en el centro (Figura 1). La válvula aórtica era tricúspide y se identificó un aneurisma en la unión sinotubular del seno de Valsalva derecho (Figura 2) y un desgarro intimal transversal e irregular de $8,5 \mathrm{~cm}$ en forma de "V" invertida, cuyo vértice estaba situado por encima del ostium de la coronaria derecha (Figura 3 ). Este desgarro era el origen de una disección de aorta cuya pared externa estaba rota en el punto indicado previamente. La permeabilidad de la coronaria derecha estaba preservada. El resto de las coronarias, válvulas y miocardio no mostraban alteraciones.

Microscópicamente se observó una disección en la porción externa de la media (Figura 4). La pared de la aorta presentaba interrupción de las fibras elásticas quedando grandes espacios vacíos (degeneración quística de la media) (Figura 5). El plano de disección estaba tapizado por fibroblastos (Figura 6) y en el epicardio periaórtico existía tejido de granulación con numerosos eosinófilos y áreas de hemorragia (Figura 7). En el borde de la rotura de la pared externa de la disección había fibrina y numerosas plaquetas (Figura 8). Estos hallazgos eran indicativos de que la disección se había producido varios días antes (probablemente en relación al dolor torácico referido) y de que la rotura de la pared externa era reciente y la causa del taponamiento cardiaco y de la muerte súbita.

El estudio químico-toxicológico determinó 0,48 g/l de alcohol en sangre y 0,65 g/l en humor vítreo.

\section{Discusión}

La raíz de la aorta está constituida por el anillo fibroso (que se continúa con la inserción del velo anterior del anillo mitral), las valvas semilunares, los senos de Valsalva y la unión sinotubular. Por encima de ésta comienza la aorta ascendente. Se define el aneurisma de aorta como cualquier dilación de aorta desde el anillo aórtico (fibroso) a la bifurcación de la 

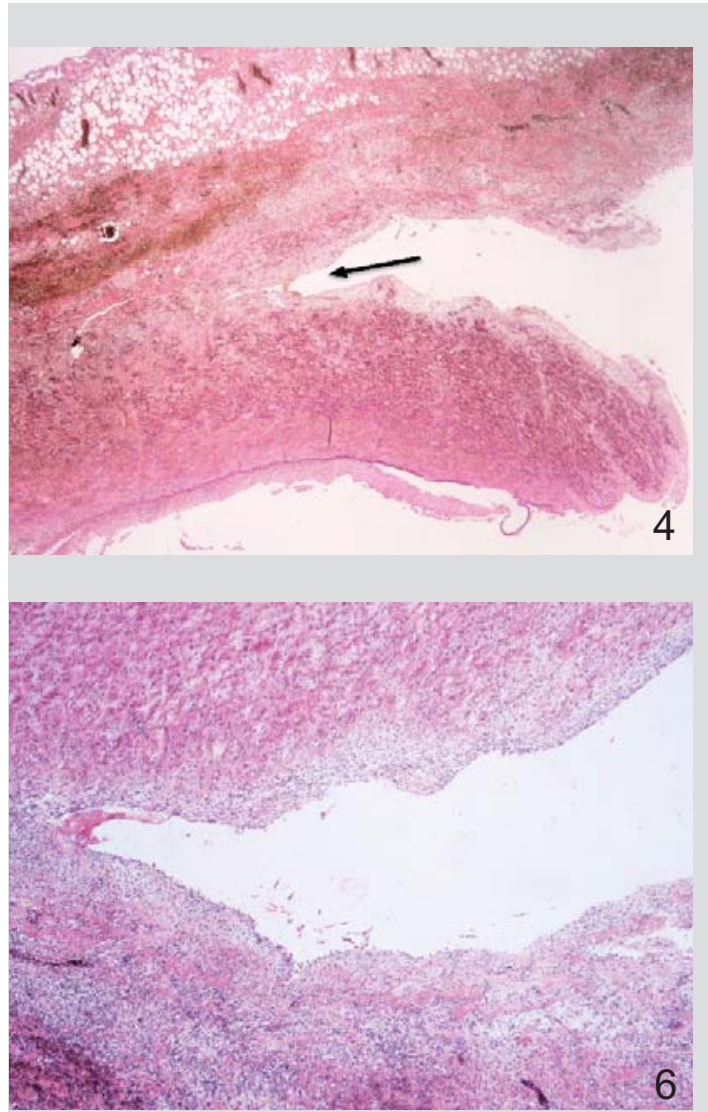

aorta abdominal. Los aneurismas de la porción proximal de la aorta pueden corresponder a tres categorías fundamentales: aneurismas de los senos de Valsalva, aneurismas de la raíz aórtica y aneurismas de la aorta ascendente ${ }^{2}$.

Los aneurismas de los senos de Valsalva son protrusiones de los senos hacia las cavidades cardíacas, miocardio o pericardio. Lo esencial de la lesión es una debilidad de la pared aórtica que forma parte del seno de Valsalva, a través de la cual protruye paulatina y progresivamente hacia la cavidad cardiaca un aneurismas sacular en forma de dedo o calcetín ${ }^{5}$. Suelen afectar a un solo seno, generalmente el seno derecho seguidos del seno posterior ${ }^{2,5-7}$. Cuando la dilación afecta a múltiples senos se consideran ectasias anuloaórticas dentro de los aneurismas de aorta ascendente $^{1,2}$. La rotura de un aneurisma del seno de Valsalva derecho produce una fístula hacia el ventrículo derecho, mientras que los aneurismas del seno posterior pueden romperse a cavidad pericárdica y producir muerte súbita por taponamiento

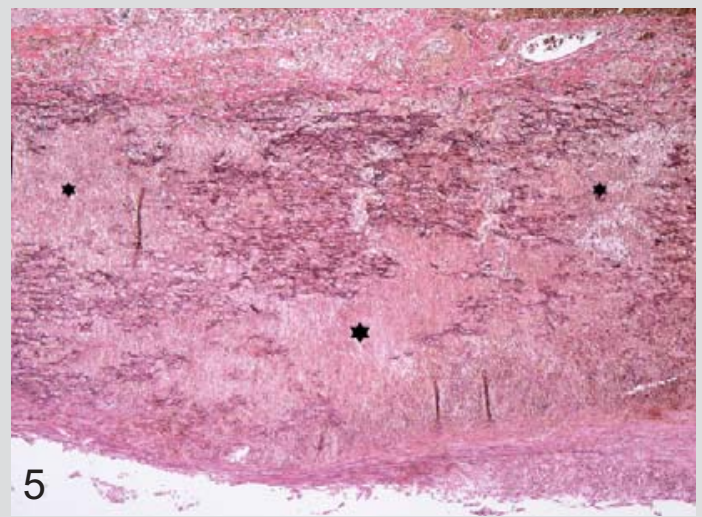

Figura 4.

Microfotografía a bajo aumento de la aorta en la zona del desgarro intimal donde se observa plano de disección en la porción externa de la media (flecha) (Tinción de Weigert para fibras elásticas, $2 x$ ).

\section{Figura 5.}

Imagen de la pared de la aorta adyacente a la disección con importante pérdida de fibras elásticas (degeneración quística de la media)(*)

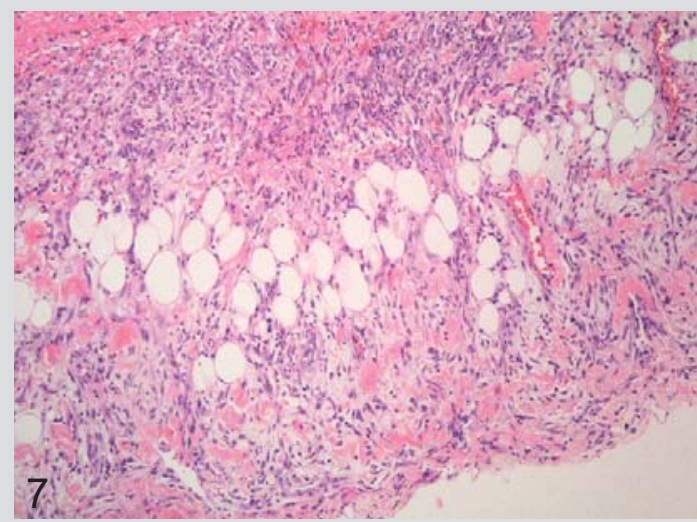

\section{Figura 6.}

Microfotografía donde se observan fibroblastos tapizando el plano

de disección (Hematoxilina-Eosina, 4x).

\section{Figura 7.}

Tejido de granulación en epicardio aórtico (Hematoxilina-Eosina, 10x).

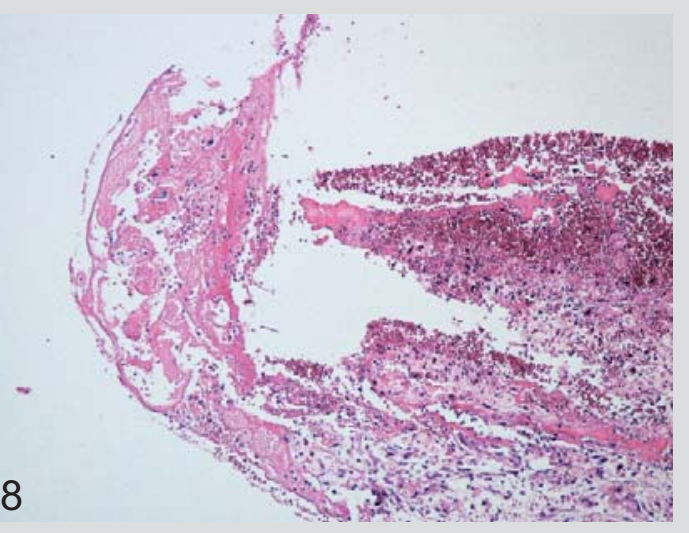

Figura 8.

Borde de la rotura de la pared externa de la disección donde se observan plaquetas, fibrina y hemorragia. (Hematoxilina-Eosina, 2x). cardiaco $^{8}$. El caso que presentamos es peculiar porque, aunque el aneurisma estaba delimitado a la unión sinotubular derecha semejando un aneurisma del seno de Valsalva, la rotura intimal, disección y degeneración quística de la media observada en el estudio anatomopatológico, indicaban un aneurisma convencional de aorta ascendente. 
Los aneurismas de la aorta ascendente pueden presentarse como patología aislada, asociados a la válvula aórtica bicúspide o formando parte de varios síndromes, los más conocidos el síndrome de Marfan, el síndrome de Ehlers-Danlos tipo IV y el sín- drome de Loeys-Dietz ${ }^{1,3,4}$. En estos cuadros se han visto mutaciones en diferentes genes que son responsables de la debilidad de la pared de la aorta. En la Tabla 1 se describen sus rasgos fenotípicos más frecuentes y los genes afectados ${ }^{3,4,9}$.

Tabla 1.

Sindromes asociados con aneurisma y disección de aorta ${ }^{3,4,9}$.

FBN1: Fibrilina 1

TGFBR: Transforming growth factor $\beta$ receptor.

COL3A1: Colágeno tipo III, $\alpha-1 .(3,4,9)$.

\begin{tabular}{|c|c|c|c|}
\hline & $\begin{array}{c}\text { Síndrome de } \\
\text { Marfan }\end{array}$ & $\begin{array}{l}\text { Síndrome de } \\
\text { Loeys-Dietz }\end{array}$ & $\begin{array}{l}\text { Síndrome de } \\
\text { Ehlers-Danlos tipo IV }\end{array}$ \\
\hline $\begin{array}{c}\text { Genes afectados/ } \\
\text { herencia }\end{array}$ & $\begin{array}{l}\text { FBN1/ } \\
\text { Aut. dominante }\end{array}$ & $\begin{array}{l}\text { TGFBR1 (tipo 1) } \\
\text { TGFBR2 (tipo 2) } \\
\text { Aut. Dominante }\end{array}$ & COL3A1 \\
\hline $\begin{array}{c}\text { Signos } \\
\text { cardiovasculares }\end{array}$ & $\begin{array}{c}\text { Dilatación de la raíz } \\
\text { aórtica } \\
\text { Dilatación de la } \\
\text { arteria pulmonar }\end{array}$ & $\begin{array}{l}\text { Disección de aorta } \\
\text { (70\% de los } \\
\text { pacientes) } \\
\text { Dilatación de la } \\
\text { arteria pulmonar }\end{array}$ & $\begin{array}{l}\text { Afecta aorta y ramas } \\
\text { distales: renales, } \\
\text { mesentéricas, ilíacas y } \\
\text { femorales }\end{array}$ \\
\hline $\begin{array}{c}\text { Hallazgos } \\
\text { histopatológicos }\end{array}$ & $\begin{array}{l}\text { Degeneración quística } \\
\text { de la media con } \\
\text { depósito de } \\
\text { glucosaminoglicanos }\end{array}$ & $\begin{array}{l}\text { Degeneración difusa } \\
\text { de la media } \\
\text { (separación de las } \\
\text { fibras elásticas) }\end{array}$ & $\begin{array}{l}\text { Mínima degeneración } \\
\text { de la media con } \\
\text { interrupción de las } \\
\text { fibras elásticas y tejido } \\
\text { fibroso organizado } \\
\text { entre ellas }\end{array}$ \\
\hline Signos cutáneos & Hernias & Hernias & $\begin{array}{l}\text { Piel aterciopelada } \\
\text { Piel translúcida } \\
\text { Equimosis } \\
\text { Cicatrización anómala } \\
\text { Acrogeria }\end{array}$ \\
\hline Signos oculares & Ectopia del cristalino & Escleras azules & Escleras azules \\
\hline Signos esqueléticos & $\begin{array}{c}\text { Aracnodactilia } \\
\text { Pectus excavatum } \\
\text { Escoliosis } \\
\text { Pies planos } \\
\text { Dolicostenomelia }\end{array}$ & $\begin{array}{l}\text { Pectus excavatum } \\
\text { Hiperlaxitud articular } \\
\text { con luxaciones }\end{array}$ & $\begin{array}{l}\text { Hiperlaxitud } \\
\text { ligamentosa } \\
\text { Hipermovilidad } \\
\text { articular }\end{array}$ \\
\hline Signos cráneo-faciales & Hipoplasia malar & $\begin{array}{c}\text { Tipo 1: } \\
\text { Hipertelorismo } \\
\text { Craneosinostosis } \\
\text { Paladar hendido } \\
\text { Úvula bífida } \\
\text { Hipoplasia malar }\end{array}$ & \\
\hline $\begin{array}{l}\text { Lesiones vasculares } \\
\text { excluyendo aorta }\end{array}$ & & $\begin{array}{l}\text { Tortuosidad de } \\
\text { vasos }\end{array}$ & $\begin{array}{c}\text { Roturas y disecciones } \\
\text { Hemorragias } \\
\text { postquirúrgicas }\end{array}$ \\
\hline Signos viscerales & $\begin{array}{l}\text { Enfisema } \\
\text { Neumotórax }\end{array}$ & & $\begin{array}{l}\text { Rotura y perforación } \\
\text { de vísceras huecas }\end{array}$ \\
\hline
\end{tabular}


Por otra parte, recientemente se ha demostrado que hasta el $19 \%$ de las personas con aneurismas de aorta torácica no tiene los síndromes previos pero varios miembros de la familia están afectados lo que indica una predisposición genética habiéndose encontrado mutaciones en tres locus situados en los cromosomas 11,5 y $3^{3}$. Aunque el tipo de herencia es autosómica dominante, la penetrancia es baja y la expresión variable ${ }^{3,10}$ por lo que estas formas familiares se diagnostican en base a la presencia de dilata- ción y/o disección de aorta torácica, ausencia de síndrome de Marfan y otras anomalías del tejido conjuntivo, e historia familiar positiva ${ }^{3}$. En nuestro caso no se encontraron rasgos fenotípicos compatibles con ninguno de estos síndromes ni tampoco ninguna otra patología cardiovascular asociada lo que parece indicar que pudiera corresponder a una forma aislada. Se ha recomendado la evaluación cardiológica de los familiares pero desconocemos el resultado de la misma.

\begin{tabular}{|c|c|c|c|c|c|}
\hline \multicolumn{3}{|l|}{$\begin{array}{l}\text { GENERAL } \\
\text { - Edad } \\
\text { - Sexo } \\
\text { - Peso } \\
\text { - Estatura }\end{array}$} & \multicolumn{3}{|c|}{$\begin{array}{l}\text { - Distancia entre brazos extendidos } \\
\text { - Longitud MMSS } \\
\text { - Longitud MMII }\end{array}$} \\
\hline & Sí & No & & Sí & No \\
\hline $\begin{array}{l}\text { CABEZA } \\
\text { - Dolicocefalia } \\
\text { - Fisuras palpebrales } \\
\text { oblicuas hacia abajo } \\
\text { - Ectopia cristalino } \\
\text { - Hipoplasia malar } \\
\text { - Micrognatia } \\
\text { - Paladar curvo }\end{array}$ & & & $\begin{array}{l}\text { - Otras malformaciones } \\
\text { craneales } \\
\text { - Distancia cantos internos } \\
\text { - Distancia cantos externos } \\
\text { - Úvula o paladar hendido } \\
\text { - Retrognatia } \\
\text { - Dientes apiñados }\end{array}$ & & \\
\hline $\begin{array}{l}\text { CARDIOVASCULAR } \\
\text { - Dilatación raíz aórtica } \\
\text { - Aneurisma aorta } \\
\text { ascendente } \\
\text { - Dilatación art. Pulmonar } \\
\text { - Válvula aórtica } \\
\text { bicúspide } \\
\text { - Persistencia ductus } \\
\text { arteriosus } \\
\text { - CIA / CIV }\end{array}$ & & & $\begin{array}{l}\text { - Disección de aorta } \\
\text { - Aneurisma/disección de } \\
\text { otras arterias. } \\
\text { - Tortuosidad arterial } \\
\text { - Coartación de aorta } \\
\text { - Otras malformaciones }\end{array}$ & & \\
\hline $\begin{array}{l}\text { PULMON } \\
\text { - Enfisema }\end{array}$ & & & - Bullas & & \\
\hline $\begin{array}{l}\text { ESQUELETO } \\
\text { - Escoliosis } \\
\text { - Pectus excavatum } \\
\text { - Pectus carinatum } \\
\text { - Otras malformaciones } \\
\text { torácicas } \\
\text { - Protusión acetabular } \\
\text { - Aracnodactilia } \\
\text { - Camptodactilia } \\
\text { - Pies largos y estrechos }\end{array}$ & & & $\begin{array}{l}\text { - Espondilolistesis } \\
\text { - Ectasia dural lumbosacra } \\
\text { - Dolicostenomelia } \\
\text { - Longitud mano } \\
\text { - Longitud dedo medio } \\
\text { - Pie zambo }\end{array}$ & & \\
\hline $\begin{array}{l}\text { OTROS } \\
\text { - Escasa masa muscular } \\
\text { - Estrías }\end{array}$ & & & - Escasa grasa subcutánea & & \\
\hline
\end{tabular}

Tabla 2.

Formulario para la recogida de datos de autopsia en caso de aneurisma de aorta (Tomado de Ripperger et al [10]). 
Algunos autores señalan características histopatológicas distintivas de unos síndromes respecto a otros ${ }^{4}$ pero de forma general en todos estos cuadros existe degeneración quística de la media, incluso en los aneurismas secundarios a hipertensión arterial, por lo que el estudio histopatológico no es suficiente para un diagnóstico definitivo ${ }^{4,10}$. En la autopsia es esencial un examen externo e interno cuidadoso de la piel, esqueleto, cráneo, cara y todas las vísceras para descartar una forma sindrómica y guardar muestra de sangre y tejidos en fresco para estudios genéti$\cos ^{10}$. En la Tabla 2 se propone un formulario de signos físicos a buscar en el examen externo del cadáver tomado de Ripperger et al para el diagnóstico diferencial de las enfermedades del tejido conectivo. Estamos de acuerdo con el comentario de estos autores según el cual aunque la Recomendación $n^{\circ}$ (99)3 del Consejo de Ministros de los estados miembros para la armonización metodológica de las autopsias médico-legales ${ }^{11}$ establece que en los casos de muerte súbita en que los hallazgos de autopsia tras un examen somero explican la causa del súbito desenlace (por ejemplo hemopericardio y rotura aórtica) no requieren más estudios, "desde un punto de vista genético el drama no termina con el diagnóstico de un aneurisma disecante de aorta sino que el acto genético puede ser de crucial importancia para la familia del fallecido" 10 .

\section{Bibliografía}

1. Burke A, Tavora F. Noninflammatory thoracic aortic aneurysms. En: Practical cardiovascular pathology. Edited by Wolkers Kluwer/Lippincott Williams \& Wilkins, Philadelphia 2001;pp.490-505.

2. Ring WS. Congenital heart surgery nomenclature and database project: aortic aneurysm, sinus of Valsalva aneurysm, and aortic dissection. Ann Thorac Surg 2000;69:S147-63.

3. Caglayan A.O. Dundar M. Inherited diseases and syndromes leading to aortic aneurysms and dissections. Eur J Cardiothorac Surg 2009;35:931-40.

4. Jain D, Dietz HC, Oswald GL, Maleszewski JJ, Halushka MK. Causes and histopathology of ascending aortic disease in children and young adults. Cardiovasc Pathol 2011;20:15-25.

5. Alva $C$, Vázquez $C$. Aneurisma congénito del seno de Valsalva. Revisión. Rev Mex Cardiol 2010; 21(3):104-10

\section{Conclusiones}

Del caso que presentamos podemos extraer las siguientes conclusiones / consideraciones:

- Hay aneurismas de aorta ascendente que pueden afectar a una parte de la unión sinotubular de la aorta semejando aneurismas de los senos de Valsalva.

- Es necesaria una cuidadosa inspección externa e interna del cadáver en casos de disección de aorta, sobre todo en jóvenes, para identificar formas sindrómicas asociadas a la misma.

- Las formas aisladas no-sindrómicas también tienen agregación familiar por lo que siempre hay que investigar los antecedentes familiares y recomendar su estudio cardiológico.

- Al igual que en otras causas de muerte súbita (como las miocardiopatías y canalopatías) en las disecciones de aorta hay que introducir los estudios genéticos (autopsia molecular) en la investigación postmortem para detectar mutaciones que permitan un diagnóstico etiológico y pueden estar presentes en otros miembros de la familia. Por ello, es conveniente conservar muestra de sangre en EDTA y tejido en fresco congelado a $-80^{\circ} \mathrm{C}$ en todos estos casos.
6. Feldman DN, Roman MJ. Aneurysms of the sinuses of Valsalva. Review. Cardiology 2006;106:73-81.

7. Moustafa S, Mookadam F, Cooper L, Adam G, Zehr K, Stulak J, Holmes D. Sinus of Valsalva aneurysms47 years of a single center experience and systematic overview of published reports. Am J Cardiol 2007;99:1159-64.

8. Golzari M, Riebman JB. The four seasons of ruptured sinus of Valsalva aneurysms: case presentations and review. Heart Surgery Forum 2004; E577-E583.

9. Colorado Casado de Amezúa A, Fernández Bayón J. Síndrome de Loeyz-Dietz. Diagnóstico diferencial en muerte súbita por disección aórtica. Rev Esp Med Legal 2009;35:70-3.

10. Ripperger T, Tröger HD, Schmidtke J. The genetic message of a sudden, unexpected death due to thoracic aortic dissection. Foresic Sci Int 2009;187:1-5.

11. Recomendación $n^{\circ}(99) 3$ del consejo de ministros de los estados miembros, para la armonización metodológica de las autopsias medicolegales. Rev Esp Med Legal 1999; XXIII:86-7. 